Fecha de recepción: octubre 2019

Fecha de aceptación: diciembre 2019

Versión final: noviembre 2021

\section{Transgresión y glamour, las portadas de la moda. Un análisis de la pasarela/ vidriera de papel}

Valeria Scalisse *

Resumen: Las revistas de moda siempre fueron la pasión de muchísimas mujeres, ajenas o relacionadas al mundo de la moda. Para analizar ¿Cómo tratan las revistas femeninas hoy en día este tema? ¿Es una mirada descontextualizada de la realidad? ¿Son las portadas de la revista un reflejo de la actualidad o son solo aspiraciones y utopías de lo que se quiere ser? Se tomarán como eje de la investigación, Vogue Italia, Vogue España y Harper's Bazaar Argentina. Según estas revistas ¿Es el planteo de la editorial algo masivo o es sólo para las minorías? ¿Qué nos propone el diseño editorial en las portadas sus publicaciones de moda? ¿Cuáles son sus líneas de diseño, sus iconos, sus marcas y qué detalles hacen a la comunicación gráfica de moda a través del papel?

Palabras clave: transgresión - portadas - diseño editorial - glamour - revistas - gráfica imagen - aspiracional.

[Resúmenes en inglés y portugués en las páginas 229-230]

${ }^{(*)}$ Diseñadora Gráfica especializada en Packaging, Universidad de Palermo. Profesora de la Universidad de Palermo, Facultad de Diseño y Comunicación.

\title{
Introducción
}

En esta investigación hacemos un paralelismo en el cual suponemos que la portada de la revista es como una pasarela de papel para la moda, y por ella desfilan imágenes que no se atienen tanto a lo teórico si no que enfatizan el rol comunicacional de la imagen, que va muchas veces más allá de lo que el lector espera y de lo que la moda vende. Crear conciencia social y relacionar el glamour con temas de la actualidad social femenina.

El diseño editorial de revistas femeninas, sus portadas y la moda, generan una triada en la que se puede ahondar a la hora de analizarlas como fenómeno social, cultural y artístico. Lo que nos ofrecen será análisis de este estudio. 
Para encuadrar nuestro marco de investigación y poder llegar a conclusiones objetivas necesitamos definir qué significa transgresión en el contexto de las portadas de moda. Que significa aspiración y que es el glamour.

Transgredir que viene del latín transgredior, trasgressus y transgressio significa el paso de un lugar a otro, generalmente saltando un obstáculo, al aplicarlo metafóricamente a las normas sociales llegamos al sentido que tiene en castellano: infringir, quebrantar, vulnerar o desobedecer una orden. Por eso es que la transgresión está tan asociada al límite, y sobre todo a cuestiones referidas a la ética. Podemos utilizar el término con una connotación positiva cuando desobedecer nos posibilita desarticular prejuicios y tabúes arraigados en la cultura. Ante la ambigüedad que nos plantea el término transgresión, optaremos en este análisis por no otorgarle connotaciones negativas.

La aspiración es el deseo intenso de conseguir una cosa que se considera muy importante. Como consumidores, siempre tenemos motivos para querer o desear algo más, y las revistas femeninas nos brindan los modelos de todo lo que podemos ser (o no ser). Este concepto también tiene un enfoque negativo y bastante cuestionado, cuando se usa para comunicar modelos, actores o situaciones que parecen mejores de lo que son en la vida real, para que el consumidor se identifique y "aspire" a ser como ellos.

En tercer lugar el glamour es otra de las palabras que dan eje a nuestro trabajo. El término glamur o glamour proviene de la palabra grammar, y se utilizada para referirse a los sabios practicantes del ocultismo y las artes mágicas. Hace alusión al encanto natural que poseen las personas o las cosas. Originalmente era un hechizo mágico que afectaba la percepción visual de una persona, mostrando los objetos percibidos de una manera diferente de la real y presentándolos de forma atractiva, magnífica o glorificada. Recién en el siglo XIX, se redujo a un término que describe la belleza y la elegancia que conforman las características de un objeto, de una manera ilusiva o romántica. Se utiliza frecuentemente en la moda para nombrar las características atractivas del modo de vestir, el estilo y la belleza intrínseca; reforzando la estética, el exceso, la vanidad, la atracción sexual.

\section{Las revistas de moda, un poco de historia}

Antes de llegar a las publicaciones elegidas, recordemos que las revistas de moda nacen en 1639 cuando en Inglaterra se edita Lady's Mercury, pero recién en el siglo XIX logran conquistar a su público. Originalmente su rol era informar sobre temas de moda y otros variados referidos a los quehaceres de la mujer.

Hacia 1759 se edita la primera publicación femenina en Francia, el Journal des Femmes, pero el contexto de analfabetismo que sufrían las mujeres en ese momento no favoreció su aceptación. Algunos años después se publica en Italia Giornale della donna galante ed erudita (1780).

Pero hubo que esperar muchos años para que la prensa femenina asuma el rol con el que la identificamos hoy en día. Puntualmente Vogue una de las revista que tomamos como referencia para esta investigación nació en 1892 en Estados Unidos. Llegó a Italia en 1964 
y hoy se edita en más de 20 países. Entre ellos encontramos la versión española desde el 1988. Ambas se siguen editando en la actualidad.

La otra publicación elegida Harper's Bazaar fue fundada en 1867 en los Estados Unidos también. Es una publicación que si bien tiene que ver con la moda no se centra solo en ello, aporta estilo y elegancia y acepta diferentes corrientes de información.

\section{Vidrieras de papel. Cómo debe ser la tapa de una revista}

"Algo que a todos les gustaría que incluyera el puesto de jefe de redacción, es la fórmula secreta para una portada triunfadora" afirma en su libro Kirstie Clements (2014, p. 114). La portada de una revista tiene diferentes funciones. Proteger a la publicación es su función corpórea, pero no es la única ni la más importante, además debe señalar el carácter editorial y el contenido de ese número. Es a la vez un cartel que promueve esa información y una síntesis muy cuidada del desarrollo de la nota de tapa.

Una tapa memorable para el editor es la que más se vende, pero esto, no siempre depende de lo que se hace. Sólo cuando la publicación es de distribución gratuita, no existe la imperiosa necesidad de ganar lectores. Según las teorías básicas del diseño editorial, una buena tapa muestra un rostro completo, a tamaño natural y con la mirada dirigida a la cámara, sin olvidar que la sonrisa debe ser encantadora y debe haber la mayor cantidad de títulos posibles. Ya se refutará esta idea en la visión que tenía Franca Sazzoni para desarrollar las portadas de Vogue Italia, y se confirmará en la edición que publica Vogue España y Harper's Bazzar.

También la tapa genera un sistema visual que debe ser coherente a lo largo del tiempo, debe relacionar las publicaciones entre si y el diseño de tapa con el desarrollo del interior de ese número. Se pone así de manifiesto el perfil de la revista. Las constantes que hacen que esto sea posible son la marca, la tipografía, la grilla, la paleta cromática y el tratamiento de las imágenes.

La potencia narrativa de la tapa también es un elemento que suma importancia. Y el discurso de las imágenes se debe desarrollar según los rasgos particulares del perfil de los lectores. Por ejemplo la versión Norteamericana y la Italiana de Vogue si bien tienen similitudes, difieren significativamente en el tratamiento tipográfico. Vogue España es más parecida a la primera.

El director de arte en equipo con el jefe de redacción y el fotógrafo deben generar imágenes atractivas y dinámicas, esto requiere siempre de planificación previa y es fundamental la pregnancia y la pertinencia temática que se logre con ellas. Se define más adelante como diferenciar la foto de prensa de la foto ilustración.

Clasificaremos a las portadas en tres categorías, figurativas, abstractas y tipográficas, pero centraremos el desarrollo en las figurativas ya que son las que más pertinencia tienen para el análisis.

La portada figurativa contiene como principal elemento una foto ilustrativa, y en el caso de las publicaciones de moda, generalmente son de un rostro o de una figura humana. Rara vez se encuentra solas en la página, ya que se la debe combinar con otros elemen- 
tos visuales que refuerzan o afirmar su significado. El grado de simplicidad, elegancia, convencionalidad o transgresión que tengan estas imágenes serán los permitidos por el público que las consume. El equipo editorial es el responsable de determinar el tono de la comunicación.

La portada no solamente es ilustrativa ya que debe contener componentes legales como la fecha de publicación, el código de barras y los datos de la edición, que si bien ningún diseñador elegiría, son de carácter obligatorio, es un desafío de organización incluirlos sin que entorpezcan el esquema general.

La marca de una revista cumple la función de reconocimiento y es uno de los elementos más importantes, debe ser legible y de formas simples, para permitir que los cambios de color que habitualmente sufre no le quiten su pregnancia. La marca de la revista que suele ser en la mayoría de los casos un logotipo se transforma en un ícono, el cual se reconoce a simple vista y en muchos casos sin ni siquiera representarse en su totalidad, haciendo en este caso alusión a la ley de continuidad visual y de reconocimiento de la parte por él todo. Lo que raramente se modifica de esta constante es la ubicación y la tipografía, aunque en diseño no hay leyes obligatorias que lo impidan.

Los títulos nos explican de forma lingüística cual es el contenido de la publicación, suelen ser, salvo que uno este subscripto a una revista, los responsables de la venta. Se dividen en principal y secundarios. Lo realmente importante a la hora de plantarlos en la grilla de tapa es saber jerarquizar el contenido de manera correcta, dando importancia a la nota de tapa y utilizando el resto como complemento. Si no hay jerarquías no hay mensaje claro, si todos gritan, nadie escucha. Algunas publicaciones son minimalistas en el titulado de sus tapas y otras son exclusivamente tipográficas como enunciamos en las categorías, pero estas no son pertinentes al área de la moda.

El color de la marca y la titulación en la tapa se suelen elegir para generar contraste con la imagen de fondo o por el contrario armonía cromática. Está decisión de diseño se toma teniendo siempre en cuenta el mensaje que se quiere comunicar, el color es un factor determinante en como percibimos la publicación, los colores pueden generar sensaciones de espacio, temperatura y otros efectos asociados a la psicología del color.

\section{La fotografía de moda con factor periodístico}

Antes de que la fotografía inundara las revistas de moda, los diseños de ropajes con las últimas tendencias de las cortes europeas, que solían marcar la pauta, llegaban a la clientela en forma de grabados. (...) Las láminas incluían una descripción del modelo y el tipo de tejido utilizado. De ahí que se consideren precursoras de publicaciones tan famosas hoy como Harper's Bazaar o Vogue (El País, 12/06/2015).

Hoy en día la fotografía lejos de ser una imagen objetiva, está cargada de subjetividad (encuadre, punto de vista, lente utilizado, etc.) y connotaciones dadas por quienes la crean. La fotografía periodística es una manera de informar, pero no por ello debe repetir lo que 
dice el texto, si no que al ser un lenguaje complementario debe enriquecerlo. Podemos ver dos categorías diferentes, la foto de prensa documental y la foto ilustración.

Es la segunda categoría la que nos aporta a esta investigación porque se utiliza para recrear situaciones, ambientes o personajes, que pueden estar relacionados con la actualidad o ser atemporales. Las condiciones de producción son generadas por los integrantes de la editorial con el fin de ilustrar determinada información. Se puede realizar en estudios con escenografía e iluminación o en ámbitos naturales.

Este tipo de imagen permite la utilización de técnicas de distorsión que las hagan más atractivas, ya que su código de lectura es siempre la artificialidad con la que fue generada.

\section{Vogue Italia y su editora}

Hablar de transgresión en el contexto de las revistas de moda y no nombrar a Franca Sozzani (1950-2016) es algo imposible. La reconocida editora de Vogue Italia durante 28 años es "la reina de esa controversia por el impacto que sus fotografías han causado en todo el mundo, para algunos son ofensivas, para otros son arte sofisticado y muchos creen que son la cúspide de la moda" dice Forbes en el documental "Franca: Chaos and Creation" que filmo su único hijo Francesco Carrozzini .

Vogue Italia es una revista publicada por Condé Nast International, y pese a ser la edición menos comercial que existe de la marca es una de las más influyentes en el mundo de la moda en los últimos 29 años. Desde que Franca asume ese cargo en el año 1988 la revista adquiere una imagen vanguardista, impactante y provocativa. Se la considera una de las mejores versiones de Vogue, superando a la versión norteamericana.

Franca aporta un nuevo estilo, una nueva visión de la moda. "Vogue antes de Franca, hacia una revista para su mercado, a menudo una revista hermosa, y ella destrozó el esquema" confiesa el director de Condé Nast en el documental que la homenaje. Ella pensaba que las revistas eran sumamente aburridas y comerciales, y pensaba que Vogue podía llegar mucho más alto que cualquiera antes. Por eso ha ido tras imágenes no convencionales, porque de eso mismo se trata la moda.

Junto con la editora se suma al equipo Steven Meisel, fotógrafo, encargado de retratar todas las portadas de la revista sin interrupción hasta el año 2015.

Las portadas de Vogue son minimalistas en el tratamiento de los textos, pero de alto voltaje en la temática y estilo fotográfico. No es casual que el fotógrafo sea el mismo que fotografío a Madonna para su libro Sex, en el año 1992. El trabajo de Meisel es controvertido, y utilizó Vogue Italia como plataforma para crear diseños que combinan la moda, la política y los conflictos sociales más estandarizados.

Algunas de las portadas más icónicas de esta dupla fueron las que analizamos a continuación, pero nos centraremos solo en algunas de ellas para profundizar en el tema que se plantea en la investigación.

En junio de 2005 y bajo el nombre de Makeover Madness la línea que separa la ficción de la realidad no podría haber sido más estrecha. La editorial fotografiada por Steven Meisel mostraba un grupo de modelos sometidas a diversas cirugías plásticas, acompañadas por 
sus enfermaras y recuperándose en el hotel St. Regis envueltas en sus abrigos de piel (Ver Figura 1). La construcción casi simétrica de la foto en su composición y la sobriedad de la imagen, la marca y la tipografía de los títulos (Makeover Madness) se contraponen de manera exagera al tema que plantea. Si bien las lectoras de Vogue pertenecen a un público heterogéneo, también se puede deducir que una parte de ellas son mujeres millonarias obsesionadas por la belleza. Esta portada no es inocente ni pasa inadvertida, por el contrario y lejos de ser una portada simplemente de moda, toma el rol de crítica social y de cuestionamiento sobre los estándares de belleza de la época. Franca solo quería transmitir la realidad.

Pero quizá fue la portada de Septiembre de 2007, que mostraba de forma casi monocromática a una de las modelos más populares de la época (Agyness Deyn) cubierta de pintura y tierra, y rodeada de un grupo de soldados bajo la palabra "Extraordinary", una de las más cuestionadas. La editorial bajo el título Make Love not War, refleja de manera glamorosa la temática de mujeres que fueron abusadas por soldados en bases militares (Ver Figura 1).

La editorial, publicada en el año considerado como el más violento de toda la Guerra de Irak, causó controversia inmediatamente: algunos como The Guardian dijeron que las imágenes eran "las imágenes de moda más insoportables e insípidas de la historia”, otros más culparon a Sozzani, Meisel y la publicación en general de su poco tacto por querer hacer a la Guerra de Irak un tema glamuroso (sic), las feministas la odiaron por presentar a la mujer como un objeto sexual con el único propósito de divertir a las tropas; mientras tanto otros la alabaron por su crudeza y el hecho de que nadie tuvo miedo a presentar lo que verdaderamente pasa en las bases militares (The Crystal Shower, 2016).

Otro recurso usado en las portadas son las ediciones temáticas, The Black Issue, una edición en la que todas las modelos son negras, en julio del 2008, fue el primer número de Vogue en la historia que tuvo dos reimpresiones. Fue la edición que todos quisieron tener, y la temática que lo hizo tan interesante fue la postura que tomó contra el racismo (Ver Figura 1). Hoy sigue siendo un icono de la moda y se llega a pagar 2.500 euros para conseguir un número de esa edición.

La catástrofe sucedida en abril de 2010 en el Golfo de México, fue uno de los derrames de petróleo más desastrosos de la historia, y otra de las polémicas temáticas para la portada y la editorial del número de agosto de la revista. La modelo fue mostrada como una de las sobrevivientes entre las 8332 especies que murieron en el desastre. La intención de la producción Water \& Oil fue capturar la realidad de la situación en el lugar (Ver Figura 1). The Curvy Issue en junio 2011, trato de repetir el fenómeno de la Vogue negra usando modelos plus-size en lencería que aparecían en la portada y a lo largo de toda la edición. El fin, celebrar a las mujeres con algunos kilos de más, que según la editora se veían muchas veces más bellas y femeninas (Ver Figura 1). También hubo una edición China en junio del 2015, la última producida en la era Sozzani. Para ella se plantearon 4 portadas, todas generadas por diferentes fotógrafos (Ver Figura 2). 

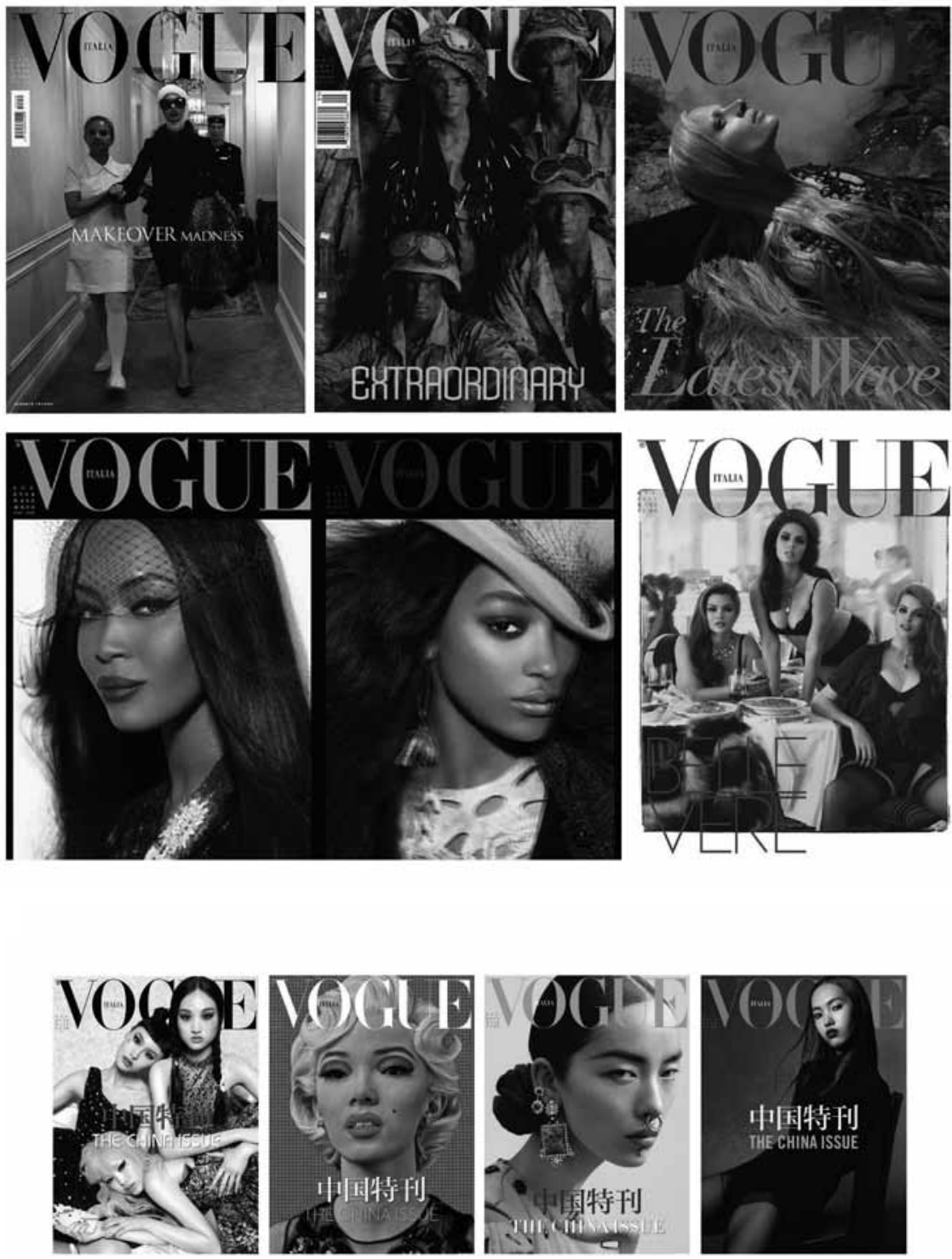

Figura 1 (arriba). Material reimpreso de las ediciones de Vogue Italia. Fotógrafo Steven Meisel. Makeover Madness, junio de 2005. Make Love not War, septiembre de 2007. Water \& Oil, julio del 2008. The Black Issue, julio del 2008 y The Curvy Issue, junio 2011 en ese orden. Figura 2 (abajo). Material reimpreso de la edición de Vogue Italia China Issue, junio del 2015. Fotógrafos: Mario Sorrenti, Steven Klein, Mert \&amp y Craig McDean en ese orden. 
Cuando Franca falleció nadie dejó de recordarla con palabras que la engrandecen.

Su mirada revolucionaria hizo posible un número dedicado en su totalidad a la lucha contra el racismo, otro que abordaba la cirugía estética como componente de la vida moderna y más temas tabú como la rehabilitación. Se encargó de encontrar un punto de conexión entre temas de rabiosa actualidad (el petróleo, el hambre, la guerra...) y la moda con una actitud valiente y contestataria (Ana Poyo, 2016).

Nunca sabremos cómo habría sido Vogue Italia sin la presencia de Franca. Actualmente la publicación está bajó la dirección de Emanuele Farneti, quien a simple vista cambió radicalmente la política y estética de las portadas de la revista, transformando a estas en imágenes más convencionales y relacionadas al ámbito de la moda, donde si bien aparece cierta estética transgresora, son en general criticadas por la falta de originalidad temática.

\section{Vogue España, tradición y belleza clásica}

Mientras que en Vogue Italia abundan las imágenes fuera de lo convencional, su par española es tradicional y conservadora.

La edición española nace en 1988, y luego de afrontar diferentes retos la publicación se compromete con la moda patria, el apoyo a los diseñadores nacionales y la difusión de noticias relacionadas con las tendencias de moda mostradas por las marcas de lujo internacional. Sus temas centrales son la moda, la belleza y los estilos de vida, aunque también se puede encontrar contenido sobre nutrición, ocio, eventos, música, tecnología, bodas y actualidad política.

Además de ser la más leída del mercado es el referente principal de la moda. Según un estudio realizado por la empresa sobre la audiencia, se analizó el mercado y se determinó el perfil del público. Lo que concluyeron fue que: sus lectoras destacan por su estilo de vida; ponen el foco sobre sí mismas; les gusta el cambio y las novedades; son prácticas y positivas, buscan la estabilidad y el consenso en sus decisiones, pero por sobre todo esto son tradicionales y les gusta la rutina.

Si se tiene en cuenta este perfil, se puede entender porque a diferencia de la edición italiana, la versión española opta por un estilo de portadas menos controversiales y carentes de transgresión.

Así lo enuncia María Paz Hinojosa Mellado, en su tesis escrita en la Universidad de Murcia (España) en 2007. 

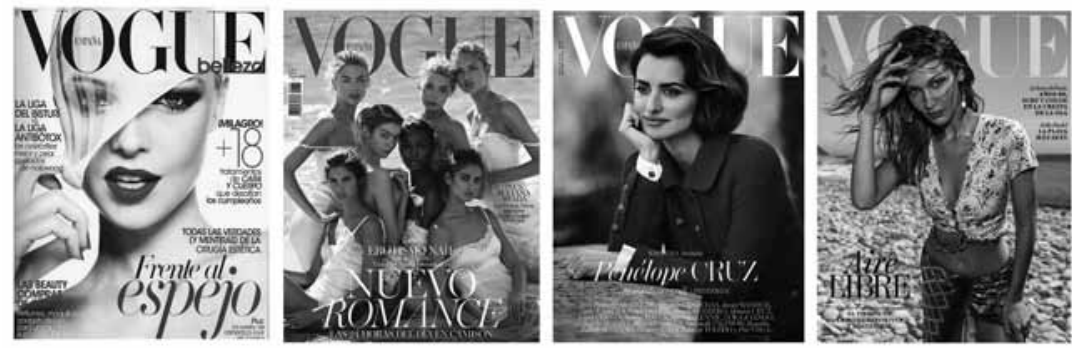

Figura 3. Material reimpreso de las ediciones de Vogue España. Tapa Botox noviembre de 2013 y otras tapas Clásicas de Vogue España (mayo 2016, abril 2019 y mayo 2019 en ese orden)

También la americana Vogue, editada por Condé Nast, triunfa en España. No son estas las únicas novedades destacables. Las remodelaciones en el sector y los avances tecnológicos dan lugar a un diseño más elaborado, a una abundancia de color, etc. Pese a los cambios y novedades, todas estas publicaciones siguen la estela de las revistas de moda nacidas en el Romanticismo, pero no debemos olvidar las de corte más revolucionario, que se vieron obligadas a desaparecer en el franquismo y que intentaron triunfar con el asentamiento de la democracia. Veremos, sin embargo, que siempre han tenido un carácter muy minoritario y que en España, al revés de lo que ha sucedido en el resto de Europa, nunca han gozado de aceptación.

Vemos a lo largo de la selección de portadas elegidas, cómo la estética de estas tapas se sitúa en el extremo opuesto al caso anterior. Un ejemplo, la portada de noviembre de 2013 (Ver Figura 3) presenta el tema de las cirugías y el botox, lejos de hacer una crítica hacia la temática en sí y poner de manifiesto su postura, el titulo de tapa promete revelar quienes son las celebrities mejor o peor operadas de Hollywood y cuáles son las verdades y las mentiras sobre el tema. El abordaje estético de la imagen es tradicional, los colores que predominan, el negro, blanco y rojo, también lo son y la actitud de la modelo es tal cual la plantea la línea más teórica del diseño editorial, citado en este texto. Esto no implica que la tapa sea incorrecta, sino que marca diferencias en el estilo y la política de la editorial. Si bien se investigó con el fin de encontrar ejemplos que contradigan esta fórmula, no aparecen a lo largo de los 31 años que tiene la revista en España casos significativos o relevantes que demuestren que la publicación comunica el glamour asociado a la transgresión. Por el contrario si se ve que maneja una imagen limpia, simple, de alta calidad estética y refinamiento, representado como bien espera su público que la marca siga siendo sinónimo de estilo y elegancia. 
En otro continente la editora de Vogue Australia, enuncia con acierto la postura que elige la edición española para diseñar sus tapas

La mayor preocupación de un editor es producir, mes a mes, una portada que venda. (...) Claro, esto se decidía después de lidiar con fotógrafos que querían que todo se pareciera a Vogue Italia, publicación que a mi parecer, está en un nivel que nadie alcanza. Es inigualable. Pensar en imitarla ya es pretencioso. Además, copiar a Vogue Italia, sería como el beso de la muerte para Vogue Australia en lo que se refiere a ventas (Clements, 2014, p. 118).

\section{Harper's Bazzar, ¿Cómo fue su edición Argentina?}

La edición Argentina se lanzó en mayo de 2011 y fueron Ana Torrejón y Claudia Pasquini, las encargadas de dirigirla. Cuando la revista llegó al país se juzgó conveniente que los 144 años de historia que tenía debían ser respetados y se rescataron los valores que funcionaban como eje para el contrato visual y de lectura que hacen a la identidad de la publicación. Pero no por ello dejo de ser una revista hecha de manera local, con contenido global, pensando en el lector argentino. Para construir una identidad propia la edición se aferró a coincidencias económicas, culturales e históricas del mundo de la moda que encontró en las otras 24 ediciones que tiene la firma. Harper's Bazzar se define en argentina como una revista que aborda el tema de la moda en búsqueda de diálogo con la cultura.

Veamos ahora como es la postura que toma esta revista a la hora de construir las portadas. A nuestro entender se sitúa entre el tono transgresor de Vogue Italia, y el conservador de Vogue España, acercándose más a la versión española.

En la edición de diciembre de 2016 la editorial se titula: "ser bella es ser diversa" y muestra a la Srta. Bimbo, modelo plus size, animándose así a modificar los estereotipos que hacen a las modelos de tapa (Ver Figura 4). En 2015 lo hace usando al Actor Benjamín Vicuña, no muchos hombres protagonizan las portadas de revistas femeninas. Pero ese es otro tema (Ver Figura 4).

También reivindica algunos valores culturales cuando es su edición de los 5 años de la revista, se muestra una modelo vistiendo el traje típico de gaucho, pero pareciendo de alta costura (Ver Figura 4).

Más allá de estos ejemplos seguimos viendo que lo que prevalece como tono de comunicación son las modelos clásicas y las celebrities nacionales.

En 2017 y por problemas económicos se cerró la redacción local, pero la revista se sigue vendiendo y contiene material generado de manera local con edición y dirección de Harper's Bazzar México.

Glosario de otras publicaciones.

Además de las tres publicaciones elegidas y analizadas el mundo editorial de la moda tiene más ejemplos que refuerzan y/o contradicen las ideas de transgresión y glamour en su política editorial. Veamos en el siguiente listado algunas de las más conocidas. 

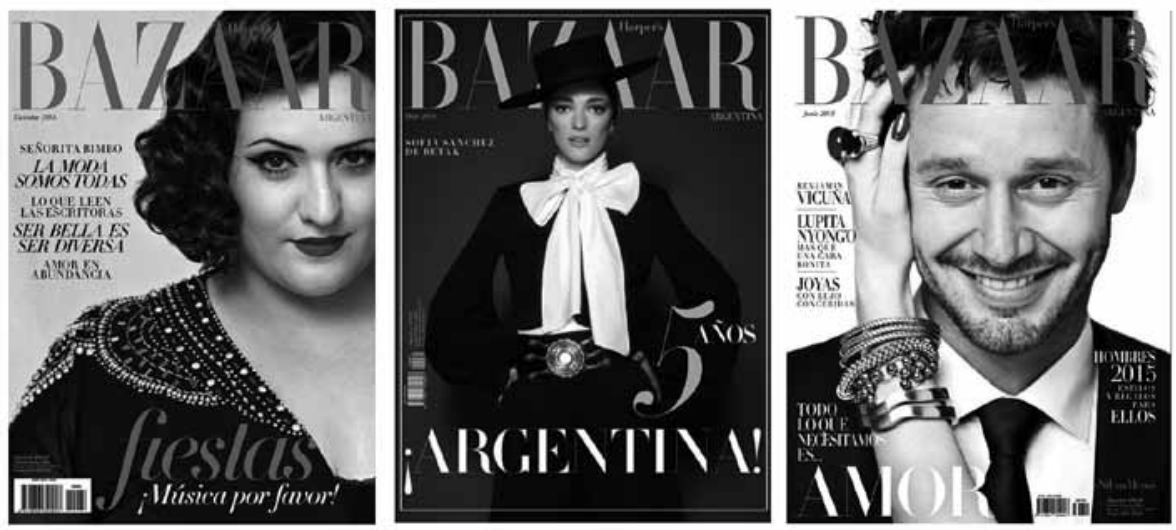

Figura 4. Material reimpreso de las ediciones de Harper's Bazzar Argentina. Srta. Bimbo, Diciembre 2016. Gaucho, mayo 2016 y Benjamín Vicuña, junio 2015 en ese orden.

Cosmopolitan es conocida por su naturaleza provocativa. El foco es el sexo y las citas, pero también hurga en la moda y el bienestar físico. Se publica hace más de un siglo y comenzó siendo una revista familiar. Tiene lectoras en más de 100 países y es publicada en 32 idiomas. Elle Magazine se enfoca en moda, belleza, salud y entretenimiento. Sus fundadores fueron Pierre Lazareff y su esposa Hélène Gordon en el año 1945. Hoy en día cuenta con 8 publicaciones que se editan en 28 idiomas. En Argentina la edita el Grupo Clarín desde 1994. Glamour es otra revista para mujeres publicada mensualmente por Condé Nast Publications. Se creó en 1939 en Estados Unidos, originalmente se llamaba Glamour of Hollywood. En la actualidad se publica en numerosos países.

InStyle proporciona una guía accesible para el usuario de lo que es tendencia en el momento. No aborda el tema de la alta costura. Se edita desde 1994 en Estados Unidos y se distribuye en 16 países. En 2018, fué la primera revista de moda importante que prohibió el uso de fotografía y anuncios de pieles.

L'Officiel de la couture et de la mode de Paris es una revista de moda francesa. Está dirigida a mujeres con elevados ingresos. En los años ochenta, fue la primera revista francesa que se comenzó a editar en China, y hoy en día, disponen de treinta ediciones extranjeras en veinte países.

Marie Claire se inició en Francia en 1937, pero también se distribuye en otros países con ediciones específicas para sus idiomas. Cada país muestra un tono especial según sus lectoras, Pero la edición de Estados Unidos está enfocada de manera global.

Nylon, sacude a la industria de la moda. Se inspira tanto en las calles como en las pasarelas de Londres y Nueva York, y se enfoca principalmente en la interacción entre música y 
moda. Es moderna, divertida e intrépida, Nylon fué cofundada en 1999, y actualmente se edita en Japón, Korea, Indonesia, Singapur. Tailandia, China. Alemania (primera publicación europea de la revista) y Latinoamérica.

Ohlalá salió al mercado en el 2008 editada por el grupo La Nación, con la misión de "compartir y debatir los temas que viven las mujeres argentinas" Si bien no es exclusivamente de moda, aborda el tema en una de sus secciones fijas a lo largo de todos sus números.

Para Ti es una revista semanal y argentina dedicada a la mujer, creada por la Editorial Atlántida en 1922. En sus páginas propone producciones y artículos de moda, belleza, decoración, cocina, entretenimiento e información general. Tiene varias ediciones especiales en el año: Colecciones primavera-verano, Colecciones otoño-invierno, Especial Belleza, Edición Aniversario y Especial Navidad. Es una de las revistas nacionales más reconocidas. Surface despega del resto de las publicaciones y propone una mezcla perfecta de moda, arquitectura, diseño, cultura y viajes y lo traduce en arte que se puede usar. Se edita en Estados Unidos, 4 veces al año desde 1993.

T Magazine la revista The New York Times Style, combina el estilo ingenioso de New York Times con la elegancia de la pasarela de moda. De corte intelectual.

Vanity Fair prueba que la moda no es solo superficial. Cubre temas de actualidad, política y cultura pop, la revista es informativa y sofisticada. La publicación se revivió en 1983 y actualmente incluye cinco ediciones internacionales (Reino Unido, España, Francia, Italia y México).

W Magazine es otra revista de moda estadounidense, mensual y publicada por Condé Nast Publications. De corte más controversial, plantea portadas y relatos que generan respuestas diversas en su público.

\section{Conclusiones}

Hemos visto a lo largo de estas páginas como las publicaciones elegidas optan cada una de ellas por un tono particular, Vogue Italia es la más osada y significativa a la hora de hablar de transgresión, sobre todo cuando Franca Sozzani la editaba y Harper's Bazar Argentina y Vogue España son más glamorosas y elegantes.

Las revistas femeninas de moda en la actualidad, son un reflejo de lo que aspiramos a ser las mujeres, pero los ejemplos que nos muestran siguen siendo muy difíciles de alcanzar. Los estereotipos de modelos, el maquillaje, los peinados, la ropa, los accesorios y demás, son un reflejo de la artificialidad que conlleva la producción fotográfica creada con este fin. De hecho ni las modelos que posan para esas fotos son así naturalmente.

Creemos que más allá de las diversas temáticas que tratan los editores en sus publicaciones, las revistas femeninas hoy en día, siguen siendo para una minoría, que no solo goza de poder adquisitivo, sino que además prefiere leer en formato papel y dedicar tiempo a estar desconectado de una pantalla, y destacamos esto porqué si bien no fue el tema de la investigación las publicaciones online influyen hoy en día en la venta y elección de los formatos impresos. 
En algunas portadas empezamos a ver imágenes que tratan de ser un poco más reales (aunque no en su totalidad) y en otras las producciones son completamente utópicas, la utopía por definición es "un lugar que no existe".

En las portadas analizadas vemos como de a poco se va asumiendo mayor compromiso social, hablando de violencia de género y de racismo; tratando temas tabú, como la adicción y las cirugías o planteando editoriales que exceden el sector de la moda, y asumen el compromiso de eliminar los estereotipos. Pero esto aún es muy incipiente como para determinar si se logrará cambiar el paradigma actual de belleza femenina, aunque la diversidad sea el tema que está de moda.

\section{Lista de Referencias Bibliográficas}

Carrozzini, F. (2016). Franca: Chaos and Creation. Netflix

Clements, K. (2014). Vogue, secretos impactantes de la marca más emblemática del mundo de la moda. México: Editorial Aguilar.

Declay, E. (2014). Franca Sozzani: Vogue Italia's Queen Of Controversy.Forbes. Recuperado de: www.forbes.com/sites/declaneytan/2014/10/07/franca-sozzani-vogue-italias-queenof-controversy/\#5acabc877841

Ferrer, I. (2015). La moda antes de las revistas. España. Recuperado de: https://elpais.com/ cultura/2015/06/12/actualidad/1434118455_151553.html

Hinojosa Mellado, M. (2005). La persuasión en la prensa femenina: análisis de las modalidades de la enunciación. Murcia: Universidad de Murcia. Recuperado de: http://hdl.handle. net/10803/10943

Lescano, V. (2011). El lanzamiento de Harper's Bazaar en la Argentina. Buenos Aires: Pagina 12. Recuperado de: www.pagina12.com.ar/diario/suplementos/las12/13-6545-2011-0608.html

Luque Ortiz, S. y Pérez Curiel, C. (2018). El empoderamiento femenino en las revistas de moda ¿Realidad o aspiración? España: RIHC. Recuperado de: www.academia. edu/38551778/EL_EMPODERAMIENTO_FEMENINO_EN_LAS_REVISTAS_DE_ MODA._REALIDAD_O_ASPIRACIÓN

Owen, W. (1991). Diseño de Revistas. Barcelona: Gustavo Gili.

Poyo, A. (2016). Fallece Franca Sozzani. España. Recuperado de: www.vogue.es/moda/news/ articulos/muere-franca-sozzani-2016/27774

Romper con los estereotipos: el éxito de las portadas de revistas con modelos plus size. (2018). Recuperado de: www.infobae.com/tendencias/lifestyle/2018/07/02/romper-con-losestereotipos-el-exito-de-las-portadas-de-revistas-con-modelos-plus-size/

Swann, A. (1990). Como diseñar retículas. Barcelona: Gustavo Gili.

Traversa, O. (2009). Por qué y cómo estudiar las tapas de las revistas: el papel de la noción de dispositivo. Buenos Aires: IUNA. Recuperado de: www.revistafiguraciones.com.ar/ numeroactual/ articulo.php\%3Fida\%3D108\%26idn\%3D5\%26arch\%3D1

Vogue 30 años. (2018). España. Recuperado de: www.cnworld.es/pdf/mk-vogue.pdf 


\begin{abstract}
Fashion magazines were always the passion of many women, outside or related to the world of fashion. To analyze: How do women's magazines treat this issue today? Is it a decontextualized view of reality? Are the covers of the magazine a reflection of current affairs or are they only aspirations and utopias of what you want to be?

Vogue Italia, Vogue España and Harper's Bazaar Argentina will be taken as the axis of the investigation. According to these magazines, Is the editorial's approach somewhat massive or is it only for minorities? What does editorial design propose to us on the covers of your fashion publications, what are their design lines, their icons, their brands and what details do they make to fashion graphic communication through paper?
\end{abstract}

Keywords: transgression - covers - editorial design - glamor - magazines - graphics - image - aspirational.

Resumo: As revistas de moda sempre foram a paixão de muitas mulheres, alheias ou relacionadas ao mundo da moda. Para analisar ¿Cómo tratam as revistas femininas hoje em dia este tema? ¿É uma mirada descontextualizada da realidade? ¿São as capas da revista um reflexo da atualidade ou são só aspirações e utopias do que quer ser sido?

Se tomarão como eixo da pesquisa, Vogue Italia, Vogue España y Harper's Bazaar Argentina. De acordo com essas revistas, ¿É o proponho da editorial algo em massa ou é só para as minorias? ¿Que nos propõe o design editorial nas capas de suas publicações de moda? ¿Quais são suas linhas de design, seus ícones, suas marcas e daí detalhes fazem à comunicação gráfica de moda através do papel?

Palavras chave: Transgressão - capas - design editorial - glamour - revistas - gráfica - imagem - aspiracional.

[Las traducciones de los abstracts fueron supervisadas por el autor de cada artículo] 